Article

\title{
The Effect of Proactive Personality on Creativity: The Mediating Role of Feedback-Seeking Behavior
}

\author{
Heesun Chae ${ }^{1}\left(\mathbb{D}\right.$ and Jisung Park ${ }^{2, *}$ \\ 1 College of Business Administration, Pukyong National University, 45 Yongso-ro, Nam-gu, \\ Busan 48513, Korea; hschae@pknu.ac.kr \\ 2 School of Business, Chungnam National University, 99 Daehak-ro, Yuseong-gu, Daejeon 34134, Korea \\ * Correspondence: jspark1@cnu.ac.kr
}

check for updates

Citation: Chae, H.; Park, J. The Effect of Proactive Personality on Creativity: The Mediating Role of Feedback-

Seeking Behavior. Sustainability 2022, 14, 1495. https://doi.org/10.3390/ su14031495

Academic Editors: Naoum Mylonas and Hyo Sun Jung

Received: 3 November 2021

Accepted: 26 January 2022

Published: 27 January 2022

Publisher's Note: MDPI stays neutral with regard to jurisdictional claims in published maps and institutional affiliations.

Copyright: (c) 2022 by the authors. Licensee MDPI, Basel, Switzerland. This article is an open access article distributed under the terms and conditions of the Creative Commons Attribution (CC BY) license (https:// creativecommons.org/licenses/by/ $4.0 /)$.

\begin{abstract}
While the effects of a proactive personality on creativity have been well established, the behavioral mechanism underlying this relationship remains poorly understood. This study suggests the salience of the mediating mechanism of feedback-seeking behavior in explaining the process by which proactive individuals can perform creative outcomes. Specifically, based on the two axes-the types (inquiry vs. monitoring) and the methods (frequency vs. breadth) — this study proposes that four methods of feedback-seeking behavior (frequency of feedback inquiry, breadth of feedback inquiry, frequency of feedback monitoring, and breadth of feedback monitoring) mediate the relationship between the proactive personality and creativity. The results, which are based on data collected from 367 individuals across Korean companies, reveal that the proactive personality has a significant indirect effect on creativity via two methods only: frequency of inquiry and frequency of monitoring. Finally, this study represents a theoretical and practical contribution to academic research on creativity and proactivity in the workplace.
\end{abstract}

Keywords: proactive personality; feedback-seeking behavior; frequency of feedback inquiry; breadth of feedback inquiry; frequency of feedback monitoring; breadth of feedback monitoring; creativity

\section{Introduction}

In today's rapidly changing and decentralized environment, managers cannot anticipate all situational contingencies in advance and struggle to specify behaviors that they expect from employees [1]. Organizations must increasingly rely on employees' personal initiative to identify and solve problems [2]. Consequently, personality traits-particularly those that reflect a willingness to change-are increasingly recognized as a driver of competitive advantage both within and for an organization $[3,4]$.

A proactive personality describes an individual's natural inclination toward promoting constructive changes [5-7]. Empirical evidence suggests that employees who exhibit this trait are more highly engaged in additional job activities beyond the formal requirements of their roles [8] and take initiative to change procedures while executing tasks [2]. As highlighted in a recent systematic literature review of the literature [9], very few studies have investigated the effects of proactive personality on creativity. Furthermore, researchers have not yet carefully examined mediating factors through which a proactive personality finds expression in creativity-enhancing ways [9-11]. Crant and Bateman [12] have also called for more research showing the intervening mechanisms that link proactive personality to work outcomes.

To fill this gap, some studies have explicitly attempted to identify mediating links through which personality manifests itself to augment creativity, such as network building [13], relational approaches (LMX [14]), cognitive mechanisms (role breadth self-efficacy and flexible role orientation [8]), and motivational mechanisms (information exchange and psychological safety [15]). However, the behavior mechanism has not been examined in such a way as to incorporate the relationship between the proactive personality 
and creativity. On this specific point, Crant [1] notes that it is rare for a study to integrate proactivity-related constructs to examine which specific proactive behaviors are uncommon. While a proactive personality is designed to capture a proactive behavioral tendency toward enacting one's environment [5], feedback-seeking behavior is also proactive behavior that individuals might use to gather job-related insights [16,17].

As a direct response to answer the research need, this study investigates how a specific proactive behavioral mechanism mediates the relationship between proactive personality and individual creativity. Proactive people do not sit around waiting for opportunities to come; rather, they frequently scan for them and actively find chances to improve situations by seeking feedback. The consideration that individuals' attempts to enhance their own creative performance through feedback-seeking represents an expansion of the usual thinking about this phenomenon, moving the research beyond merely a focus on adaptation and individual conformation with the demands of an organization [18]. Specifically, feedbackseeking enables proactive individuals to adapt and respond to continuously changing goals and role expectations to achieve greater compatibility between one's own attributes and the organizational environment $[17,19]$, thus leading to creative outcomes.

As a path to connect the effect of proactive personality on creativity, this study considers the feedback-seeking options available to employees, such as two different types of information that they can seek (inquiry vs. monitoring) and two different methods by which they can act opportunities through direct inquiry or inference of feedback [16,20]. Specifically, individuals with proactive personalities seek out opportunities through direct inquiry or inference of feedback. The more frequently a proactive individual directly asks for or monitors feedback, the more valuable and credible the assets they will receive for their work will be [21]. They also seek feedback from various sources within their work environments, such as from supervisors, coworkers, and subordinates, and as well as extra-organizational sources, providing inputs to improve situations and solve problems. By widely gathering feedback from different sources, proactive employees can accumulate informational resources related to their work situations and their own performances $[7,21]$. The accumulation of informational resources is critical for creativity and is considered to be a preparatory stage for the generation of a response. In short, this study analyzes how each of the four methods of feedback-seeking behavior differently mediates the relationship between the proactive personality and creativity, depending on the two axes of the types and the methods.

As a result, this study may help researchers to gain a closer understanding of the multifaceted nature of feedback-seeking behavior and to learn how to unpack the behavioral mechanisms underpinning creative performance. The study's theoretical framework is illustrated in Figure 1 and elaborated on below.

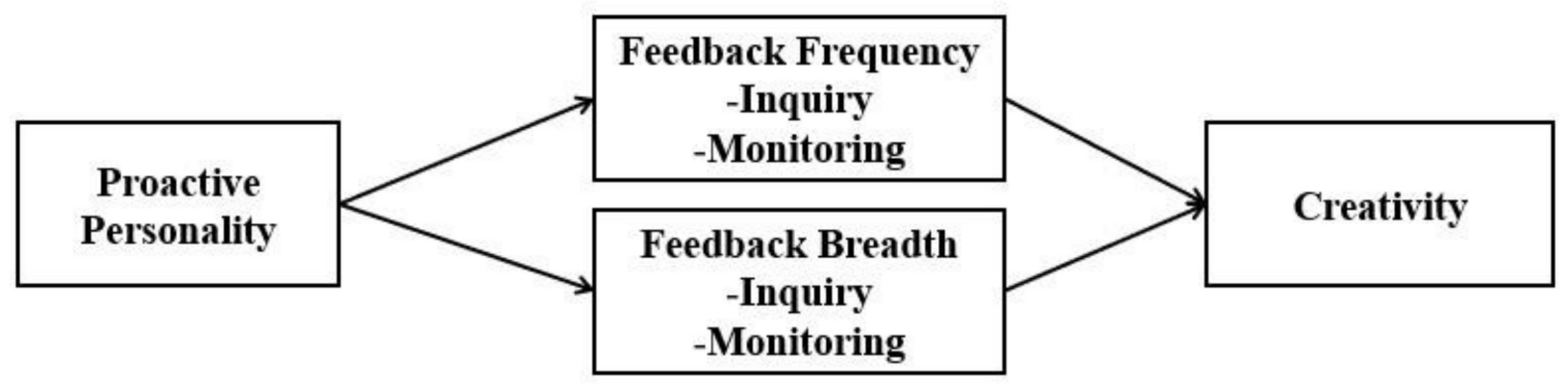

Figure 1. Conceptual framework.

\section{Theory and Hypotheses}

\subsection{The Proactive Personality and Creativity}

People do not always behave passively to environmental constraints; on the contrary, they often respond proactively to alter their current circumstances [1]. Bateman and Crant [5] suggest utilizing a proactive dispositional construct to identify differences among 
those who proactively influence their environments. Proactive people initiate actions to seize opportunities and to persevere in the hope of bringing about meaningful change [1,12]. They are also more likely to focus on future-oriented actions, to plan for changes in advance, and to improve either their current situations, themselves, or both [2,22]. In contrast, passive people are reactive, receiving their current situational dynamics without influencing change. Passive people have a high tendency to adapt to and endure their environments [1]. Mostly, they fail to initiate change or seek out opportunities for improvement.

Proactive people are also pathfinders and, as such, they redefine what performance means while also transforming their organization's mission. Consequently, they tend to identify broad-scale problems and correct them. In fact, because they feel a personal responsibility for constructive change [22], they try to enhance circumstances and develop new procedures. These characteristics allow proactive people to anticipate future events and respond in such a way as to foster effective and positive change $[6,23]$.

Not only does the proactive personality represent an action-oriented variable, but the construct is also paralleled with many definitions of creativity. Typically, creativity is defined as the generation or production of novel and useful ideas [24]. Furthermore, because creative behaviors include "coming up with new and better ways of doing things" [24] (p. 682), creativity inherently challenges the status quo and operates on a future-oriented vision, which is a common factor in most forms of the proactive personality. This certainly fits the following definition of proactivity: "identify opportunities and act on them, show initiative, take actions" [1] (p. 439). Similarly, identifying problems and opportunities is an important aspect of the creative process, and the creative people's focus on generating new ideas reflects an action-based orientation. Based on this common behavioral trait between proactive and creative people, proactive individuals have a strong tendency to initiate positive change in their jobs and organizations: thus, they are also more likely to be creative [25]. It is therefore predicted that:

\section{Hypothesis 1. Proactive personality is positively correlated to creativity.}

\subsection{The Proactive Personality and Feedback-Seeking}

Crant [1] argued that it is advantageous to examine the extent to which individual proactive characteristics have informed the academic literature on specific proactive behaviors. The literature on feedback-seeking behavior indicates the following: (1) that an important weakness is a lack of awareness regarding the role of individual dispositional differences in the feedback-seeking process [26], and (2) that individuals are not simply "passive recipients" of feedback, but that they actively search for feedback.

Feedback-seeking is far from a straightforward process. In fact, numerous studies provide diverse feedback-seeking models available to employees. Specifically, in Ashford and his colleagues' review of feedback-seeking behavior [26], they identified five key feedback-seeking patterns in related studies that have been conducted over the past twenty years. The identified patterns are (1) frequency (how often individuals seek feedback); (2) method (whether sought directly by inquiry or indirectly by monitoring); (3) timing; (4) the identified target; (5) the topic. For the purposes of investigating the mediating role of feedback-seeking in the proactive personality/creativity relationship via cross-sectional data, two aspects of feedback-seeking identified from Ashford will be considered, omitting timing and topic as factors.

Feedback-seeking types vary based on how people seek feedback. One possibility is for employees to seek feedback directly by asking others. This type, which this study refers to as "inquiry", is an explicit verbal request for feedback. Proactive individuals engage in this pattern of proactive feedback-seeking behavior voluntarily and also anticipate ways through which they can gain information about their behavior [16,19]. Monitoring is the second type of feedback-seeking behavior and is clearly differentiated from inquiring [26]. Monitoring is when proactive individuals obtain information by observing a situation, especially by monitoring other people. This provides them with a better understanding 
of how others are performing; how others act toward them (the seeker), and what others make informal, unsolicited, and casual remarks to others [7].

Individuals also choose how frequently they seek feedback within a given time period $[26,27]$. Frequency is an important factor that determines how proactive behaviors may differ. For example, how regularly feedback-seeking occurs could be affected by individual differences $[7,20]$. People who have proactive personalities frequently seek feedback to identify and learn new things to improve situations. Rather than waiting for direction from others, they have a behavioral tendency to seek feedback frequently, thereby gleaning information about what is happening around them. Thus, their initiative and change-oriented characteristics lead them to frequently ask questions and monitor frequently.

Hypothesis 2. The proactive personality is positively correlated with a high frequency of seeking feedback (2a: Inquiry and 2b: Monitoring).

Another key type of feedback-seeking behavior pertains to the target or sources from which the individual solicits feedback. Often, employees obtain informational cues from many different sources in their professional environment, such as from supervisors, coworkers, subordinates, and even extra-organizational sources [21,27]. Because no single specific source can offer fully comprehensive feedback, individuals may need to ask for feedback from a variety of sources, as well as monitor different targets. Only through such breadth can employees likely gain adequate information about their professional performance [28]. The more often an individual seeks feedback from multiple sources, the more likely they are to obtain enough feedback to constitute an effective evaluation. Proactive individuals are more likely to gain an advantage because they have collected more cues through inquiring and monitoring before reaching a conclusion based on the feedback gained from different sources. Thus, their proactive behavioral traits lead them to seek out different sources to receive a broader range of information.

Hypothesis 3. The proactive personality is positively correlated to a breadth of feedback-seeking (3a: Inquiry and 3b: Monitoring).

\subsection{The Mediating Role of Feedback Frequency}

Proactive employees put their efforts into increasing the amount of relevant data about their information environment by frequently asking questions and monitoring situations. By frequently seeking feedback, the proactive individual accumulates a more valuable and credible asset than passive individuals [29]. The resources (e.g., information and trust relationships) they gain from initiating actions will promote creativity in turn. In addition, by collecting information through monitoring, proactive individuals not only obtain information about how others evaluate their work but also learn what problems others are struggling with. In fact, employees who use monitoring to solicit feedback from either direct or indirect sources will have a better grasp of how other constituents behave and respond. This understanding then empowers them to identify problems that could create opportunities for improvement. The more frequently they collect cues by observing others' behavior, the better they understand why others respond to them in a particular way [28]. By understanding the situation via their feedback-seeking behaviors, proactive individuals often anticipate future incidents that are likely to happen and seize opportunities to promote desirable outcomes. Thus, proactive employees gather informational resources by inquiring and monitoring others. These behaviors allow them to generate new ways to perform their jobs and form new perspectives about improving work procedures [29].

Hypothesis 4. Feedback frequency (4a: Inquiry and 4b: Monitoring) mediates the positive relationship between the proactive personality and creativity. 


\subsection{The Mediating Role of Feedback Breadth}

Those who seek feedback from a broad range of sources often receive various kinds of information, knowledge, and perspectives regarding work issues [21]. Collecting feedback from such a diversity of sources empowers individuals to identify problems that may be causing difficulties and to identify new ways to overcome such difficulties. In addition, employees who receive their feedback from many sources may develop a better understanding of what their colleagues and other stakeholders want and need [7]. Typically, this happens because they experience smoother communications with others, thereby understanding which agendas would best serve their constituents. Indeed, accumulating resources through feedback-seeking is a crucial factor of creativity, which in turn improves an individual's knowledge base and ability to identify and solve problems innovatively. Often, proactive individuals may use their collected data to anticipate future events so as to initiate constructive changes. Thus, feedback accumulation is a valuable practice for proactive individuals; the activity guides them to find situational constraints and improve their professional contexts.

Hypothesis 5. Feedback breadth (5a: Inquiry and 5b: Monitoring) mediates the positive relationship between the proactive personality and creativity.

\section{Methodology}

\subsection{Data Collection and Samples}

The survey was conducted among various Korean companies (12 firms) in the following sectors: manufacturing, electronics, telecommunications, and construction. To minimize multicollinearity issues [30], survey data were collected from two different sources: one pertaining to the focal employee, and the second assessing the employees' immediate supervisors. Before delivering the survey packets to employees, we first gave a brief presentation about the study's purpose and explained the procedures to the supervisors. Finally, we distributed survey packets to 60 supervisors and 400 employees.

Of these initial samples, 53 supervisors and 370 employees returned the surveys directly to the researchers (supervisor response rate $=88.3 \%$; employee response rate $=91.8 \%$ ). After eliminating incomplete responses and mismatched surveys, the researchers analyzed final data sets with a sample of 367 members from 53 teams.

Of these final samples, the average employee age was $36.98(\mathrm{SD}=8.42)$ years and the average organizational tenure of the employees was 7.49 years $(\mathrm{SD}=7.68)$. The sample was constituted of $56.9 \%$ of men and $43.1 \%$ of women. Education levels ranged from high school diplomas to a doctoral degree; $6 \%$ of the respondents' highest educational level was a high school degree; $18 \%$ had completed junior college; $62.7 \%$ had earned a bachelor's; $13.4 \%$ held either a master's and or a doctoral degree.

\subsection{Measures}

To avoid common method bias, the employees were instructed to report their demographics, independent and mediating variables, whereas their immediate supervisors were asked to rate the employees' creativity. We used a seven-point scale ranging from 1 (not at all) to 7 (extremely), except for the demographic data.

\subsubsection{Proactive Personality}

We measured the proactive personality with the shortened four-item scale $(\alpha=0.84)$ of Seibert et al. [3]. An example item is "I am constantly on the lookout for new ways to improve my life".

\subsubsection{Frequency of Feedback Inquiry and Monitoring}

This study followed the methods of De Stobbeleir et al. [31] to measure the frequency of feedback inquiry and monitoring. Employees were asked to report the frequency of their engagement in feedback-seeking behaviors (inquiry and monitoring) using two items. 
These two items were then repeated with three different sources (supervisors, team members, and members of other teams), resulting in a six-item measure of inquiry ( $\alpha=0.96)$ and monitoring $(\alpha=0.92)$. Items of inquiry to supervisor include: "How frequently do you ask feedback about your work to your supervisor?" and "How frequently do you ask for advice for better ways of doing your work to your supervisor?". Items of monitoring to supervisor include: "How frequently do you pay attention to how your supervisor acts toward you in order to understand how he/she perceives and evaluates your work?" and "How frequently do you compare yourself with supervisors?". Next, the researchers calculated the average feedback-seeking frequency for the three targets; finally, the overall frequency score was computed by averaging the three values.

\subsubsection{Breadth of Feedback-Seeking Inquiry and Monitoring}

Similar to an earlier study [31], this work also employed the Herfindahl formulation to calculate the level of feedback-seeking breadth as the distribution of resources across three different feedback sources. The Herfindahl formulation "captures the 'market share' of a person's feedback-seeking that is allocated to each target of that seeking" [31] (p. 820).

Herfindahl formation $=\left(1-\left[\left\{\frac{\text { seeking from supervisor }}{\text { total seeking }}\right\}^{2}+\left\{\frac{\text { seeking from team members }}{\text { total seeking }}\right\}^{2}+\left\{\frac{\text { seeking from members of other teams }}{\text { total seeking }}\right\}^{2}\right]\right)$

With the present data of three feedback source categories, the value of the Herfindahl index showed that the breadth of feedback inquiry ranged from 0.53 to 0.67 ; the breadth of feedback monitoring ranged from 0.56 to 0.67 .

\subsubsection{Creativity}

Each employee's creativity was measured using a shortened version of the six-item scale $(\alpha=0.96)$ developed by the authors of [24]. In keeping with the methods of previous research, this study assessed creativity by using supervisor ratings [28,32]. An example item includes "Comes up with new and practical ideas to improve performance".

\subsubsection{Control Variables}

This research contained four demographic factors as control variables, such as age (in years), organizational tenure (in years), education ( $1=$ high school, $2=$ two years of college education, $3=$ undergraduate degree, $4=$ graduate degree), and gender (women $=0$; men $=1$ ). This decision was important, because these characteristics may affect employees' level of motivation to engage in feedback-seeking behaviors and show their creativity [33]. Additionally, because different tasks require different levels of creativity [34], this study also controlled for task type $(0=$ clerical, marketing, and general management; $1=$ production and engineering) and task interdependence (a five-item scale, $\alpha=0.91$ ).

\subsection{Analytical Strategy}

According to the data, the proportion of the between-group variance for creativity was $13.4 \%$ of the total variance $(p<0.05)$, which showed the presence of the supervisor effect as an outcome variable. Given this nested data structure, this study performed multistage HLM equations to consider the group-level variance, which is significant. To identify the confidence intervals of the proposed indirect effects, the researchers followed the bootstrapping procedure that Preacher et al. [35] recommended.

\section{Results}

\subsection{Validity and Reliability Analysis}

We conducted exploratory factor analysis (EFA) in order to investigate the validity of the study's measures. All items were rotated by varimax rotation under the assumption that there is no correlation among factors. We also measured Cronbach's alpha for the reliability of measures. Table 1 presents the results of the EFA and the Cronbach's alpha values. All items were clearly loaded on four factors with a significantly high reliability coefficient. 
Table 1. The results of EFA and Cronbach's alpha.

\begin{tabular}{|c|c|c|c|c|c|c|}
\hline Items & Factor 1 (Cre) & Factor 2 (In) & Factor 3 (Mo) & Factor 4 (TI) & Factor 5 (PP) & Cronbach's Alpha \\
\hline Cre1 & 0.900 & 0.101 & 0.128 & 0.002 & 0.054 & \multirow{6}{*}{0.96} \\
\hline Cre2 & 0.937 & 0.084 & 0.077 & 0.024 & 0.049 & \\
\hline Cre3 & 0.951 & 0.060 & 0.031 & 0.004 & 0.018 & \\
\hline Cre4 & 0.891 & 0.006 & 0.049 & -0.021 & 0.051 & \\
\hline Cre5 & 0.902 & 0.069 & 0.074 & 0.044 & 0.040 & \\
\hline Cre6 & 0.887 & 0.035 & 0.062 & 0.046 & 0.116 & \\
\hline InSu1 & 0.055 & 0.809 & 0.185 & 0.088 & 0.154 & \multirow{6}{*}{0.96} \\
\hline InSu2 & 0.051 & 0.796 & 0.196 & 0.138 & 0.151 & \\
\hline InTM1 & 0.057 & 0.897 & 0.210 & 0.164 & 0.062 & \\
\hline InTM2 & 0.071 & 0.909 & 0.166 & 0.139 & 0.047 & \\
\hline InOT1 & 0.078 & 0.903 & 0.141 & 0.138 & 0.085 & \\
\hline InOT2 & 0.060 & 0.912 & 0.091 & 0.119 & 0.033 & \\
\hline MoSu1 & 0.087 & 0.286 & 0.699 & 0.032 & 0.228 & \multirow{6}{*}{0.92} \\
\hline $\mathrm{MoSu} 2$ & 0.057 & 0.273 & 0.650 & 0.018 & 0.154 & \\
\hline MoTM1 & 0.094 & 0.113 & 0.873 & -0.034 & 0.032 & \\
\hline MoTM2 & 0.064 & 0.123 & 0.932 & 0.021 & 0.050 & \\
\hline MoOT1 & 0.059 & 0.128 & 0.896 & 0.088 & 0.061 & \\
\hline MoOT2 & 0.072 & 0.123 & 0.936 & 0.047 & 0.041 & \\
\hline TI1 & -0.005 & 0.153 & -0.005 & 0.825 & 0.038 & \multirow{5}{*}{0.91} \\
\hline TI2 & -0.001 & 0.052 & 0.169 & 0.867 & 0.028 & \\
\hline TI3 & 0.058 & 0.105 & 0.123 & 0.849 & 0.053 & \\
\hline TI4 & 0.022 & 0.211 & -0.055 & 0.857 & 0.028 & \\
\hline TI5 & 0.012 & 0.137 & -0.086 & 0.821 & 0.139 & \\
\hline PP1 & 0.041 & 0.187 & 0.023 & 0.076 & 0.803 & \multirow{4}{*}{0.84} \\
\hline PP2 & 0.109 & 0.139 & 0.029 & 0.119 & 0.858 & \\
\hline PP3 & 0.073 & -0.089 & 0.335 & -0.013 & $\begin{array}{l}0.030 \\
0.710\end{array}$ & \\
\hline PP4 & 0.054 & 0.154 & 0.108 & 0.076 & 0.805 & \\
\hline \multirow{3}{*}{$\begin{array}{c}\text { Eigenvalues } \\
\text { Variance explained (\%) } \\
\text { Accumulative variance } \\
\text { explained (\%) }\end{array}$} & 5.069 & 4.993 & 4.479 & 3.713 & 2.727 & \\
\hline & 18.774 & 18.494 & 16.588 & 13.750 & 10.100 & \\
\hline & 18.774 & 37.269 & 53.857 & 67.607 & 77.707 & \\
\hline
\end{tabular}

Abbreviation: Cre = creativity, In = inquiry, Mo = monitoring, InSu = inquiry from supervisor, InTMo $=$ in quiry from team members, InOT $=$ inquiry from other team members, MoSu = monitoring from supervisor, $\mathrm{MoTM}=$ monitoring from team members, MoOT = monitoring from other team members, $\mathrm{TI}=$ task interdependence, $\mathrm{PP}=$ proactive personality.

\subsection{Descriptive Statistics}

Table 2 provides a summary of statistics and correlations of the variables in this study. As expected, a proactive personality was positively related to the outcome variable (creativity, $\mathrm{r}=0.16, p<0.01$ ). Proactive personality was positively correlated with the frequency of inquiry $(\mathrm{r}=0.26, p<0.001)$ and the frequency of monitoring $(\mathrm{r}=0.27, p<0.001)$, but was not significantly correlated with breadth of inquiry $(r=-0.09, n s$. $)$ and breadth of monitoring $(\mathrm{r}=-0.01, n s$.). Whereas the frequency of inquiry $(\mathrm{r}=0.15, p<0.01)$ and the frequency of monitoring $(\mathrm{r}=0.18, p<0.01)$ were both found to be positively correlated with creativity, breadth of inquiry $(\mathrm{r}=0.01, n s$. $)$ and breadth of monitoring $(\mathrm{r}=0.02, n s$. $)$ were not significantly correlated with creativity.

\subsection{Hypotheses Testing}

For Hypothesis 1, this study proposed a positive relationship between a proactive personality and creativity. Firstly, the six control variables were entered into the HLM equation. Next, a proactive personality was included in the HLM equations as the main predicting factor that predicts creativity. The HLM analysis results (Model 2 in Table 3) showed that the proactive personality does have a significant and positive effect on creativity $(\gamma=0.16$, $p<0.05)$. Thus, Hypothesis 1 was supported. 
Table 2. Means, standard deviations, and inter-scale correlation.

\begin{tabular}{|c|c|c|c|c|c|c|c|c|c|c|c|c|c|}
\hline Variables & $\mathbf{M}$ & SD & 1 & 2 & 3 & 4 & 5 & 6 & 7 & 8 & 9 & 10 & 11 \\
\hline 1. Age & 36.98 & 8.42 & & & & & & & & & & & \\
\hline 2. Gender & 0.57 & 0.50 & 0.04 & & & & & & & & & & \\
\hline 3. Education & 2.83 & 0.73 & -0.03 & $0.19^{* * *}$ & & & & & & & & & \\
\hline 4. Tenure & 7.49 & 7.68 & $0.67^{* * *}$ & $0.12 *$ & -0.05 & & & & & & & & \\
\hline 5. Task Type & 0.23 & 0.42 & $-0.12 *$ & 0.06 & $0.14^{* *}$ & $-0.19^{* * *}$ & & & & & & & \\
\hline 6. Task Interdependence & 4.00 & 1.11 & -0.06 & 0.03 & $-0.12 *$ & -0.06 & 0.08 & & & & & & \\
\hline 7. Proactive Personality & 4.39 & 0.99 & $0.17^{* *}$ & $0.16^{* *}$ & 0.01 & 0.10 & -0.08 & $0.17^{* *}$ & & & & & \\
\hline 8. Frequency of Inquiry & 3.86 & 1.32 & $-0.13 *$ & 0.01 & -0.04 & -0.09 & 0.10 & $0.30^{* * *}$ & $0.26^{* * *}$ & & & & \\
\hline 9. Breadth of Inquiry & 0.66 & 0.02 & 0.08 & 0.04 & -0.04 & 0.08 & 0.06 & -0.06 & -0.09 & -0.01 & & & \\
\hline $\begin{array}{l}\text { 10. Frequency of } \\
\text { Monitoring }\end{array}$ & 4.71 & 1.03 & 0.01 & 0.03 & 0.07 & -0.01 & 0.07 & 0.11 * & $0.27^{* * *}$ & $0.39 * * *$ & -0.03 & & \\
\hline $\begin{array}{l}\text { 11. Breadth of } \\
\text { Monitoring }\end{array}$ & 0.66 & 0.01 & -0.01 & 0.03 & -0.10 & 0.01 & 0.04 & 0.08 & -0.01 & 0.09 & 0.11 * & 0.05 & \\
\hline 12. Creativity & 4.55 & 1.10 & 0.09 & 0.06 & 0.05 & 0.04 & 0.06 & 0.05 & $0.16^{* *}$ & $0.15^{* *}$ & 0.01 & $0.18^{* *}$ & 0.02 \\
\hline
\end{tabular}

Note: $\mathrm{N}=367$. Task type $(0=$ clerical, marketing, and general management; 1 = production and engineering); gender (women = 0 ; men = 1$)$; education $(1=$ high school, $2=$ two years of college education, $3=$ undergraduate degree, $4=$ graduate degree). ${ }^{*} p<0.05,{ }^{* *} p<0.01,{ }^{* * *} p<0.001$. 
Table 3. Hierarchical linear models predicting creativity.

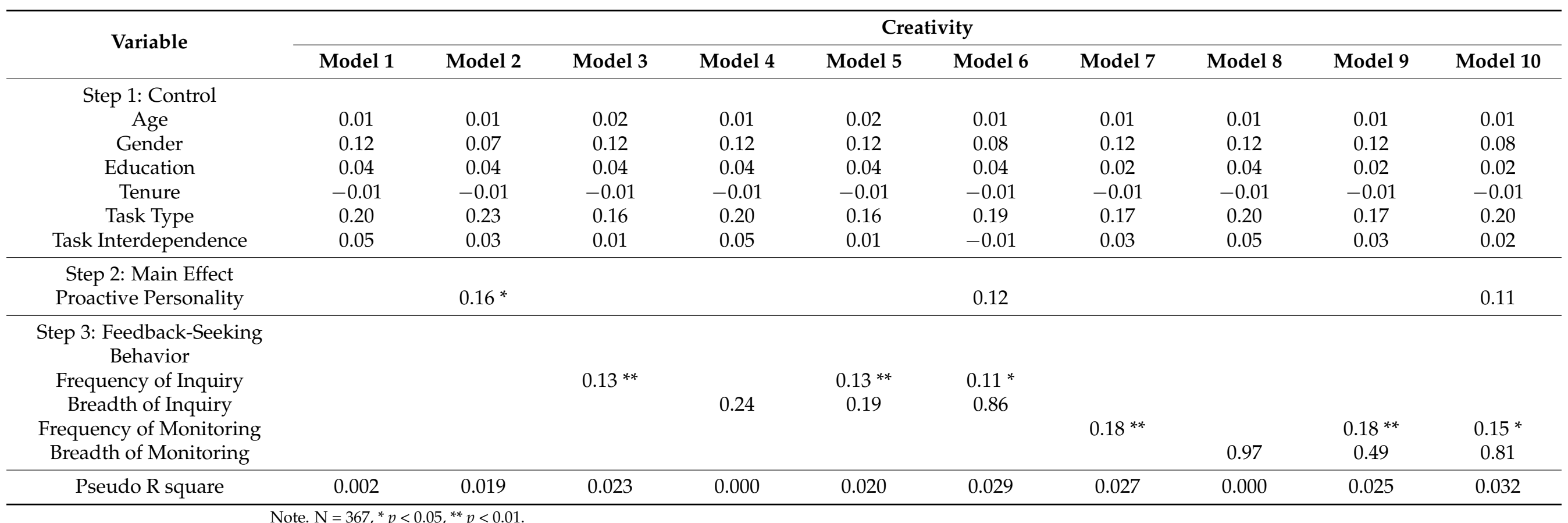


Hypothesis 2 posited that the proactive personality is positively correlated to the frequency that employees engage in feedback inquiry ( $\mathrm{H} 2 \mathrm{a})$ and monitoring $(\mathrm{H} 2 \mathrm{~b})$. Models 2 and 6 in Table 4 showed that the proactive personality was both a positive and significant predictor of frequently conducting feedback inquiries $(\gamma=0.34, p<0.001)$. However, a proactive personality was not a significant predictor of frequent feedback monitoring activity $(\gamma=-0.002, \mathrm{~ns}$.). These results provide evidence supporting Hypothesis $2 \mathrm{a}$.

Hypothesis 3 suggested that the proactive personality is positively correlated to a wide breadth of feedback inquiry (H3a) and monitoring (H3b). Models 4 and 8 in Table 4 reported that a proactive personality was not a significant predictor of breadth, neither was feedback inquiry $(\gamma=-0.002$, ns.) nor feedback monitoring $(\gamma=-0.001$, ns. $)$, respectively. Thus, Hypothesis 3 was not supported.

For Hypothesis 4, this study suggested that the effect of the proactive personality on creativity is mediated distinctly by the frequency of feedback inquiry ( $\mathrm{H} 4 \mathrm{a})$ and monitoring (H4b). To examine formally the mediation effects of the frequency of feedback inquiry and monitoring, this study employed the procedure that Preacher et al. outline [35], which enabled this study to test the confidence intervals of the hypothesized indirect effects. These results in Table 5 showed that both the frequency of feedback inquiry (indirect effect $=0.038$, $95 \%$ CI $(0.007,0.088)$ ) and the frequency of feedback monitoring (indirect effect $=0.044,95 \%$ CI $(0.012,0.100))$ significantly mediated the relationship between the proactive personality and creativity, which supports Hypothesis 4.

Hypothesis 5 posited that the effects of the proactive personality on creativity are mediated distinctly by the breadth of feedback inquiry (H5a) and monitoring (H5b). Furthermore, the results in Table 5 of the procedure outlined by Preacher et al. [35] suggest that the indirect effect of the proactive personality on creativity via the breadth of feedback inquiry (indirect effect $=-0.002,95 \%$ CI $(-0.021,0.008)$ ) and breadth of feedback monitoring (indirect effect $=-0.001,95 \%$ CI $(-0.015,0.006)$ ) was not statistically significant, which rejects Hypothesis 5.

Table 4. Hierarchical linear models predicting frequency and breadth of inquiry and monitoring predicting creativity.

\begin{tabular}{|c|c|c|c|c|c|c|c|c|}
\hline \multirow{2}{*}{ Variable } & \multicolumn{2}{|c|}{ Frequency of Inquiry } & \multicolumn{2}{|c|}{ Breadth of Inquiry } & \multicolumn{2}{|c|}{ Frequency of Monitoring } & \multicolumn{2}{|c|}{ Breadth of Monitoring } \\
\hline & Model 1 & Model 2 & Model 3 & Model 4 & Model 5 & Model 6 & Model 7 & Model 8 \\
\hline \multicolumn{9}{|l|}{ Step 1: } \\
\hline \multicolumn{9}{|l|}{ Control } \\
\hline Age & -0.018 & -0.061 & 0.000 & 0.000 & 0.002 & -0.004 & -0.000 & -0.000 \\
\hline Gender & -0.019 & -0.122 & 0.001 & 0.002 & 0.028 & -0.058 & 0.001 & 0.001 \\
\hline Education & -0.011 & -0.020 & -0.002 & -0.002 & 0.135 & 0.125 & -0.002 & -0.002 \\
\hline Tenure & 0.005 & 0.008 & 0.000 & 0.000 & 0.001 & 0.003 & 0.000 & 0.000 \\
\hline Task Type & 0.238 & 0.310 & 0.003 & 0.003 & 0.164 & 0.218 & 0.002 & 0.001 \\
\hline $\begin{array}{l}\text { Task Interde- } \\
\text { pendence }\end{array}$ & $0.345^{* * *}$ & $0.293^{* * *}$ & -0.001 & 0.000 & $0.093 *$ & 0.052 & 0.000 & 0.000 \\
\hline \multicolumn{9}{|l|}{$\begin{array}{c}\text { Step 2: Main } \\
\text { Effect }\end{array}$} \\
\hline $\begin{array}{l}\text { Proactive } \\
\text { Personality }\end{array}$ & & $0.342 * * *$ & & -0.002 & & $0.278^{* * *}$ & & -0.001 \\
\hline $\begin{array}{l}\text { Pseudo R } \\
\text { square }\end{array}$ & 0.093 & 0.154 & 0.029 & 0.029 & 0.001 & 0.071 & 0.000 & 0.000 \\
\hline
\end{tabular}

Note. $\mathrm{N}=367,{ }^{*} p<0.05,{ }^{* * *} p<0.001$. 
Table 5. Bootstrapped mediation results.

\begin{tabular}{|c|c|c|c|c|c|}
\hline \multirow{2}{*}{$\begin{array}{l}\text { Independent } \\
\text { Variable }\end{array}$} & \multirow[t]{2}{*}{ Mediators } & \multirow{2}{*}{$\begin{array}{l}\text { Dependent } \\
\text { Variable }\end{array}$} & \multirow{2}{*}{$\begin{array}{l}\text { Conditional } \\
\text { Indirect Effect }\end{array}$} & \multicolumn{2}{|c|}{$\begin{array}{c}\text { Bootstrapping Bias-Corrected } 95 \% \\
\text { Confidence Interval }\end{array}$} \\
\hline & & & & Lower & Upper \\
\hline \multirow{4}{*}{$\begin{array}{l}\text { Proactive } \\
\text { Personality }\end{array}$} & Frequency of Feedback Inquiry & \multirow{4}{*}{ Creativity } & 0.038 & 0.007 & 0.088 \\
\hline & $\begin{array}{c}\text { Frequency of Feedback } \\
\text { Monitoring }\end{array}$ & & 0.044 & 0.012 & 0.100 \\
\hline & Breadth of Feedback Inquiry & & -0.002 & -0.021 & 0.008 \\
\hline & $\begin{array}{c}\text { Breadth of Feedback } \\
\text { Monitoring }\end{array}$ & & -0.001 & -0.015 & 0.006 \\
\hline
\end{tabular}

Note. Bootstrap sample size $=1000$. Coefficients in bold indicate significant mediation.

\section{Discussion and Conclusions}

\subsection{Overall Findings}

This study aims to enhance researchers' understanding of employee dispositional proactivity (proactive personality) and self-initiated behavior (feedback-seeking behavior) in the workplace. The results of this study not only showed the direct effect a proactive personality has on creativity, but also the indirect effects that the behavioral mediating process of feedback-seeking behavior has on the relationship between the proactive personality and creativity. Specifically, the frequency of feedback inquiry and monitoring indirectly mediated the relationship between the proactive personality and creativity. However, the breadth of feedback inquiry and monitoring did not mediate the relationship between the proactive personality and creativity.

\subsection{Theoretical and Practical Implications}

A number of important theoretical and practical insights emerged from the pattern of our results. First, although previous studies have been examined the effects of proactive personality on various positive outcomes [9], this study revealed that proactive employees would engage in constructive performance, such as creativity. The results are similar to those found by Seibert et al. [25]. Individuals exhibiting a stronger proactive personality are future-focused and have an idea of the changes they want to implement [1,17]; they may work toward their goals, regardless of the costs and risks required.

Second, the results of this study provide support for the person-centered view on creativity $[10,11]$. De Stobbeleir et al. [25] argued that creativity literature has generally studied the social and organizational contexts to enhance employees' creative performance. Relatively few studies have identified the critical personality dimensions underlying creative behaviors [15]. Our study revealed that proactive individuals act in ways the organization expects them to act without waiting to be told what to do or how to behave. By seeking feedback, proactive individuals attain resources that can help individuals to gain an understanding of what is going on in the workplace. Thus, consistent with the person-centered approach, we showed proactive individual is more actively engaged in creative behaviors that had a positive effect on their performance.

Third, this study also elaborates on recent studies that address the relationship between a proactive personality and creativity through assessing and analyzing behavioral intervening mechanisms. To respond to Crant and Bateman's [12] recent suggestion, this study incorporated the proactive dispositional construct (proactive personality) to explain specific proactive behaviors (feedback-seeking behavior). As Ashford et al. [26] noted, we frame feedback-seeking behavior as a proactive, self-regulatory way by which people can improve their situations. People with proactive personalities seek feedback to find out problems and to learn new things for improving situations. They prefer a behavioral tendency to seek feedback and acquire information about what is going on around them. Thus, we extend the scope of proactivity by connecting dispositional proactive construct and proactive behavioral constructs. 
Fourth, this study theorized that feedback-seeking behavior plays a distinct mediating role in creativity by conceptualizing the different types of feedback-seeking behavior, namely, the frequency and breadth of inquiry and monitoring. This study may contribute to the corpus of academic literature on both creativity and feedback-seeking behavior in that it emphasizes the way in which these four different feedback-seeking patterns can help employees identify problems causing difficulties and find creative ways to overcome them, beyond the methods of adaptation and modification.

Results revealed that the only factor that significantly predicts creativity is the frequency of feedback-seeking behavior. Creativity is stimulated only when employees frequently solicit others' input and seek advice pertaining to their current task and by monitoring others' responses. Such task-related information then often helps employees to define problems and develop new strategies for solving those problems. These patterns are consistent with the previous studies' findings that minor improvements and adaptations can be promoted when employees frequently solicit others' input and opinions $[7,28]$. In contrast, heterogeneous inputs and opinions gained by seeking feedback broadly, and from diverse sources, may deplete cognitive resources. Tyagi et al. [36] also mentioned that the breadth of feedback-seeking can consume (and often waste) time and cognitive resources that are critical for creative idea generation. The benefits of feedback-seeking from diverse sources may quickly be compromised if employees are exposed to numerous evaluative inputs [16,21]. Therefore, identifying the behavioral mechanism that underpins creative performance may help researchers to better grasp the multifaceted nature of the construct of feedback-seeking behavior.

This study offers a significant practical implication. Previous research of creativity literature has focused on how managers can enhance creative outcomes or what tangible benefits (such as higher salaries and more frequent promotions) stimulate employees' creativity [3]. The present research suggests that instead of fostering creative performance through supervisors or tangible benefits, employees are the proactive agents to stimulate creative performance by soliciting their own feedback on their work and performance frequently and from a wide variety of sources. Because individuals with proactive personalities can be intrinsically motivated to be creative, managers should create an environment in which proactive employees can express their proactive dispositional traits well. Besides, proactive employees may achieve creative performance in their work by seeking feedback more often and more broadly from a wide variety of feedback sources.

\subsection{Limitations and Recommendations for Future Research}

Some limitations do pertain to this study, and one should interpret its findings carefully. To address this limitation specifically, a longitudinal study design could test for the causality of the relationships. Second, the current empirical study did not consider contextual factors that are important in clarifying the proposed relationships. Thus, a productive avenue for future research could include potential moderating factors in explaining the effects of the proactive personality on creativity, as well as the effects of feedbackseeking behavior. According to the trait activation theory [37], situational cues that activate individual differences in promoting trait-relevant behaviors also need to be considered. Environmental conditions, or the "feedback environment", may also affect the various feedback methods and reactions [38]. Specifically, the organizational culture might create an atmosphere in which feedback inquiry is either more or less acceptable. For example, employees may be more motivated to seek feedback frequently when the interpersonal atmosphere is safe and therefore supports perceived risky active endeavors [39]. In a psychologically safe environment, employees with a proactive personality may be more at ease with obtaining feedback.

In summation, this study obtained significant and compelling findings, despite its limitations. The researchers hope that this study motivates other researchers to explore how the proactive personality and feedback-seeking behaviors positively interact to influence creativity within organizations. 
Author Contributions: All of the authors contributed immensely. H.C. wrote the majority of the manuscript; J.P. contributed to reviewing and editing the manuscript. All authors have read and agreed to the published version of the manuscript.

Funding: This work was supported by a Research Grant from Pukyong National University (2020, CD20201344).

Institutional Review Board Statement: Not applicable.

Informed Consent Statement: Not applicable.

Data Availability Statement: Not applicable.

Conflicts of Interest: The authors declare no conflict of interest.

\section{References}

1. Crant, J.M. Proactive behavior in organizations. J. Manag. 2000, 26, 435-462. [CrossRef]

2. Bergeron, D.M.; Schroeder, T.D.; Martinez, H.A. Proactive personality at work: Seeing more to do and doing more? J. Bus. Psychol. 2014, 29, 71-86. [CrossRef]

3. Seibert, S.E.; Crant, J.M.; Kraimer, M.L. Proactive personality and career success. J. Appl. Psychol. 1999, 84, 416-427. [CrossRef]

4. Frese, M.; Kring, W.; Soose, A.; Zempel, J. Personal initiative at work: Differences between East and West Germany. Acad. Manag. J. 1996, 39, 37-63. [CrossRef]

5. Bateman, T.S.; Crant, J.M. The proactive component of organizational behavior: A measure and correlates. J. Organ. Behav. 1993, 14, 103-118. [CrossRef]

6. Crant, J.M. The Proactive Personality Scale and objective job performance among real estate agents. J. Appl. Psychol. 1995, 80, 532-537. [CrossRef]

7. Sun, J.; Li, W.-D.; Li, Y.; Liden, R.C.; Li, S.; Zhang, X. Unintended consequences of being proactive? Linking proactive personality to coworker envy, helping, and undermining, and the moderating role of prosocial motivation. J. Appl. Psychol. 2021, 106, 250-267. [CrossRef]

8. Parker, S.K.; Williams, H.M.; Turner, N. Modeling the antecedents of proactive behavior at work. J. Appl. Psychol. 2006, 91, 636-652. [CrossRef]

9. Fuller, B.J.; Marler, L.E. Change driven by nature: A meta-analytic review of the proactive personality literature. J. Vocat. Behav. 2009, 75, 329-345. [CrossRef]

10. Kim, T.-Y.; Hon, A.H.Y.; Crant, J.M. Proactive personality, employee creativity, and newcomer outcomes: A longitudinal study. J. Bus. Psychol. 2009, 24, 93-103. [CrossRef]

11. Kim, T.-Y.; Hon, A.H.Y.; Lee, D.-R. Proactive personality and employee creativity: The effects of job creativity requirement and supervisor support for creativity. Creat. Res. J. 2011, 22, 37-45. [CrossRef]

12. Crant, J.M.; Bateman, T.S. The central role of proactive behavior in Organizations. In Proceedings of the 2004 Academy of Management Annual Meeting, New Orleans, LA, USA, 6-11 August 2004.

13. Wang, X.H.; Fang, Y.; Qureshi, I.; Janseen, O. Understanding employee innovative behavior: Integrating the social network and leader-member exchange perspectives. J. Organ. Behav. 2015, 36, 403-420. [CrossRef]

14. Li, N.; Liang, J.; Crant, J.M. The role of proactive personality in job satisfaction and organizational citizenship behavior: A relational perspective. J. Appl. Psychol. 2010, 95, 395-404. [CrossRef] [PubMed]

15. Gong, Y.; Cheung, S.Y.; Wang, M.; Huang, J.C. Unfolding the proactive process for creativity: Integration of the employee proactivity, information exchange, and psychological safety perspectives. J. Organ. Behav. 2010, 38, 1611-1633. [CrossRef]

16. Anseel, F.; Beatty, A.S.; Shen, W.; Lievens, F.; Sackett, P.R. How are we doing after 30 years? A meta-analytic review of the antecedents and outcomes of feedback-seeking behavior. J. Manag. 2015, 41, 318-348. [CrossRef]

17. Parker, S.K.; Collins, C.G. Taking stock: Integrating and differentiating multiple proactive behaviors. J. Manag. 2010, 36, 633-662. [CrossRef]

18. Ashford, S.J.; Black, J.S. Proactivity during organizational entry: The role of desire for control. J. Appl. Psychol. 1996, 81, 199-214. [CrossRef]

19. Ashford, S.J.; De Stobbeleir, K.; Nujella, M. To seek or not to seek: Is that the only question? Recent developments in feedbackseeking literature. Annu. Rev. Organ. Psychol. Organ. Behav. 2016, 3, 213-239. [CrossRef]

20. Vancouver, J.B.; Morrison, E.W. Feedback inquiry: The effect of source attributes and individual differences. Organ. Behav. Hum. Decis. Process. 1995, 62, 276-285. [CrossRef]

21. Sijbom, R.B.L.; Anseel, F.; Crommelinck, M.; De Beuckelaer, A.; De Stobbeleir, K.E.M. Why seeking feedback from diverse sources may not be sufficient for stimulating creativity: The role of performance dynamism and creative time pressure. J. Organ. Behav. 2018, 39, 355-368. [CrossRef]

22. Fuller, J.B.; Marler, L.E.; Hester, K. Promoting felt responsibility for constructive change and proactive behavior: Exploring aspects of an elaborated model of work design. J. Organ. Behav. 2006, 27, 1089-1120. [CrossRef]

23. Grant, A.M.; Ashford, S.J. The Dynamics of Proactivity at Work. Res. Organ. Behav. 2008, 28, 3-34. [CrossRef] 
24. Zhou, J.; George, J.M. When job dissatisfaction leads to creativity: Encouraging the expression of voice. Acad. Manage. J. 2001, 44, 682-696. [CrossRef]

25. Seibert, S.E.; Kraimer, M.L.; Crant, J.M. What do proactive people do? A longitudinal model linking proactive personality and career success. Pers. Psychol. 2001, 54, 845-874. [CrossRef]

26. Ashford, S.J.; Blatt, R.; VandeWalle, D. Reflections on the looking glass: A review of research on feedback-seeking behavior in organizations. J. Manag. 2003, 29, 769-799. [CrossRef]

27. Ashford, S.J.; Cummings, L.L. Feedback as an individual resource: Personal strategies of creating information. Organ. Behav. Hum. Perform. 1983, 32, 370-398. [CrossRef]

28. Sung, S.Y.; Rhee, Y.W.; Lee, J.E.; Choi, J.N. Dual pathways of emotional competence towards incremental and radical creativity: Resource caravans through feedback-seeking frequency and breadth. Eur. J. Work Organ. Psychol. 2020, 29, 421-433. [CrossRef]

29. Levy, P.E.; Cober, R.T.; Miller, T. The effect of transformational and transactional leadership perceptions on feedback-seeking intentions. J. Appl. Soc. Psychol. 2002, 32, 1703-1711. [CrossRef]

30. Anderson, J.C.; Gerbing, D.W. Structural equation modeling in practice: A review and recommended two-step approach. Psychol. Bull. 1988, 103, 411-423. [CrossRef]

31. De Stobbeleir, K.E.; Ashford, S.J.; Buyens, D. Self-regulation of creativity at work: The role of feedback-seeking behavior in creative performance. Acad. Manage. J. 2011, 54, 811-831. [CrossRef]

32. Chae, H.; Choi, J.N. Contextualizing the effects of job complexity on creativity and task performance: Extending job design theory with social and contextual contingencies. J. Occup. Organ. Psychol. 2018, 91, 316-339. [CrossRef]

33. Sung, S.Y.; Antefelt, A.; Choi, J.N. Dual effects of job complexity on proactive and responsive creativity: Moderating role of employee ambiguity tolerance. Group Organ. Manag. 2017, 42, 388-418. [CrossRef]

34. Anderson, N.; Potočnik, K.; Zhou, J. Innovation and creativity in organizations: A state-of-the-science review, prospective commentary, and guiding framework. J. Manag. 2014, 40, 1297-1333. [CrossRef]

35. Preacher, K.J.; Zyphur, M.J.; Zhang, Z. A general multilevel SEM framework for assessing multilevel mediation. Psychol. Methods 2010, 15, 209-233. [CrossRef] [PubMed]

36. Tyagi, V.; Hanoch, Y.; Hall, S.D.; Runco, M.; Denham, S.L. The risky side of creativity: Domain specific risk taking in creative individuals. Front. Psychol. 2017, 8, 145-153. [CrossRef] [PubMed]

37. Tett, R.P.; Guterman, H.A. Situation trait relevance, trait expression, and cross-situational consistency: Testing a principle of trait activation. J. Res. Pers. 2000, 34, 397-423. [CrossRef]

38. Nasifoglu Elidemir, S.; Ozturen, A.; Bayighomog, S.W. Innovative behaviors, employee creativity, and sustainable competitive advantage: A moderated mediation. Sustainability 2020, 12, 3295. [CrossRef]

39. Edmondson, A. Psychological safety and learning behavior in work teams. Adm. Sci. Q. 1999, 44, 350-383. [CrossRef] 